\title{
On being thrown into phenomenological research
}

Jonathan A. Smith, Paul Flowers and Michael Larkin

Interpretative phenomenological analysis: theory, method and research.

Sage, 2009; 225 pages.

f65.00 (hbk); ISBN-13: 9781412908337

f22.99 (pbk); ISBN-13: 9781412908344

“...phenomenology is a live dynamic activity, not just a scholarly

collection of ideas." (p.33)

This text is sure to become the central work on interpretative

phenomenological analysis (IPA), a particular approach to qualitative research that has become especially popular within health psychology. It brings together for the first time in one place, a clear grounding in its philosophical underpinnings, a theoretical rationale for using the interpretative phenomenological approach to research, the translation of those concepts into the practicalities of method, some fascinating and inspiring examples of IPA research, and a reflection on issues regarding the ongoing appraisal and future development of the approach.

The intended audience is anyone who has or plans to use IPA in their research. It is written in an accessible way that invites those new to IPA to embrace the methodology as one that has grown out of key philosophical debates within phenomenology and psychology; and for those more familiar with the field, it encourages a teasing out of theoretical and pragmatic issues in situating, conducting and interpreting phenomenological work.

Final version of published review: Shaw, R.L. On being thrown into phenomenological research: a book review of J.A. Smith, P. Flowers \& M. Larkin (2009) Interpretative phenomenological analysis: theory, method and research. London: Sage. Journal of Health Psychology, 15(2), 310-312. 
The first section of the book outlines the key philosophical influences on IPA: phenomenology, hermeneutics and idiography; and introduces the work of some key thinkers, e.g., Husserl, Heidegger, Merleau-Ponty, Sartre, Schleiermacher, and Gadamer. It then proceeds to describe the particular methods of data collection and analysis used within the interpretative phenomenological approach. What I enjoyed most about this section of the book is that it brings to life the work of these key figures in the development of phenomenology, illustrating the dynamic way in which their ideas were formulated, argued about and developed over time. The original works of such phenomenologists as Husserl and Heidegger are often not easy to access (or to understand) and while the authors recommend Moran's (1999) excellent Introduction to Phenomenology for those eager to read more, I think this text provides the perfect springboard for the novice IPA researcher because it highlights the key philosophical issues that are most relevant to this methodology. We move from Husserl's transcendental phenomenology, with a succinct description of his aim to understand the essential qualities of a phenomenon that transcend the particular circumstances of their appearing, to Heidegger's Dasein and the concept of being thrown into a culture thereby emphasizing the situatedness of human experience. Then the work of Merleau-Ponty and Sartre are introduced to stress that when we talk of 'experience' as the object of phenomenological research we mean the "human predicament" (p.5). Within this we see that "the complex understanding of 'experience' invokes a lived process, an unfurling of perspectives and meaning, which are unique to the person's embodied and situated relationship to the world" (p.21).

Final version of published review: Shaw, R.L. On being thrown into phenomenological research: a book review of J.A. Smith, P. Flowers \& M. Larkin (2009) Interpretative phenomenological analysis: theory, method and research. London: Sage. Journal of Health Psychology, 15(2), 310-312. 
I found the discussion of the concept fore-structure and its role in interpretation particularly useful. The authors highlight Heidegger's distinction of phenomenon and logos within phenomenology: in order to understand the appearing of the phenomenon (which is usually hidden) we need to engage in an analytic process - logos - to help us grasp this showing. Further, both Heidegger and Gadamer introduce the possibility that, rather than needing to put one's forestructures to one side in order to understand the appearance of the phenomenon, the interaction between the fore-structure and the appearance might be bidirectional and that we may not even realise what aspects of our fore-structure are relevant until we engage in the process of making sense of the 'things themselves' as they appear to us. This emphasizes the dynamic nature of analysis within the IPA approach, the importance of immersing oneself in the data, and the need to adopt a reflexive attitude.

This section of the book continues with some tips on conducting semistructured and unstructured interviews to help generate a phenomenologically focused experiential account from participants. The section closes with some extremely useful illustrations of the phenomenological and interpretative activities involved in conducting data analysis using this approach. This includes exercises and examples from the authors' research which are equally useful for researchers, lecturers and students.

My favourite part of the book was the second ection which presents original research conducted by the authors. I felt that this section delivered well on its promise to illustrate the breadth and depth of IPA research. Moreover, it is Final version of published review: Shaw, R.L. On being thrown into phenomenological research: a book review of J.A. Smith, P. Flowers \& M. Larkin (2009) Interpretative phenomenological analysis: theory, method and research. London: Sage. Journal of Health Psychology, 15(2), 310-312. 
enjoyable to read, inspiring and I think is the book's unique selling point (or USP if we stick to acronyms). Each chapter uses the authors' own work to illustrate particular aspects of IPA research such as its commitment to the individual case, its engagement with the hermeneutic circle, the phenomenological aspects of analysis, the use of metaphor and other cultural resources in participants' sense making, the management of larger samples, and the inductive process of cross case analysis.

Jonathan Smith's detailed exposition of an individual's experience of haemodialysis is particularly powerful in illustrating the significance of the "malevolent machine [which] seems to symbolize Carole's entrapment" (p.127). Michael Larkin's analysis of the Incredible Hulk metaphor is fascinating and brings to the fore Binswanger's proposal on the significance of the concept Mitsein ('beingwith') in our understanding of the "internal logic and life-historical context of the client's world" (p.150) in making sense of psychosis. But it is Paul Flower's vivid description of his research with gay men about sex and relationships that has the most salient message for health psychology: his research leads him to conclude that "condom use, or unprotected anal intercourse, is anything but a simple health behaviour. [..] Thus the analysis is showing a fundamental dissonance between how health psychology constructs sex and how gay men report thinking about it" (p.142). This research clearly illustrated for me one of IPA's most significant advantages - it begins with the person and his/her own reflections on their experiences. This does not preclude the importance of other sorts of health psychology research; rather it proposes a way in which IPA, because of its commitment to understanding people's own sense-making (cognition), can complement work using the social cognition Final version of published review: Shaw, R.L. On being thrown into phenomenological research: a book review of J.A. Smith, P. Flowers \& M. Larkin (2009) Interpretative phenomenological analysis: theory, method and research. London: Sage. Journal of Health Psychology, 15(2), 310-312. 
models of behaviour which currently dominate much of health psychology. Like Paul Flowers, I see potential for more collaborative work across methods. For such work to be truly complementary, however, I think we need to follow Rom Harré's advocacy of a both/and approach to psychological research: there needs to be a dialogue between the researchers employing quantitative methods to test the theory of planned behaviour, for instance, and those using qualitative methods like IPA to highlight the ways in which efforts can be combined to investigate the idiosyncrasies of human experience alongside a nomothetic approach to achieve a more societal level of understanding of health behaviour.

In the final section the authors emphasize the importance of being able to identify good quality qualitative research. They propose Lucy Yardley's (2000) criteria for assessing the quality as fit for purpose in IPA research because of their resonance with the conceptualization of the human subject within phenomenology, hermeneutics and idiography. They also describe Yin's (1989) proposal of an independent audit as particularly useful in ensuring the research process is transparent thereby increasing the researcher's your chances of producing a report that the reader will be able to trust.

In the penultimate chapter the authors reflect on the central concern of IPA research: to understand those human experiences that become particularly significant within the individual's lifeworld. They discuss a number of issues including language, embodiment and emotion, and cognition. Through the work of MerleauPonty, in particular, they argue that IPA research can tackle one of the central concerns of health psychology - our embodied experience. Similarly, it is seen as a Final version of published review: Shaw, R.L. On being thrown into phenomenological research: a book review of J.A. Smith, P. Flowers \& M. Larkin (2009) Interpretative phenomenological analysis: theory, method and research. London: Sage. Journal of Health Psychology, 15(2), 310-312. 
way of teasing out the detail of our situatedness and the impact this has on our experiences of health and illness; a phenomenological health psychology project would pay equal attention to the constraints enforced upon us within the workings of contemporary society and the individual's subjective experience. And, for me, most pertinent for health psychology, following discussion regarding the appropriateness of IPA's concern with cognition, the authors spell out for the reader (with reference to the important work of Jerome Bruner) what this means for those conducting interpretative phenomenological research:

“...within the natural attitude we can remember, fantasize, reflect, make judgements, come to conclusions, have volition - all of which are examples of mental or cognitive processes. This, then, is what we mean when we say that IPA is concerned with cognition. [..] This conceptualization of cognition is dilemmatic, affective and embodied. It is complex, changeable, and can be hard to pin down, but is cognition none the less" (p.191).

I hope you enjoy reading this book as much as I have and I hope it inspires some interest in those who may not yet be convinced of the applicability and suitability of IPA research in health psychology.

\section{RACHEL L. SHAW}

School of Life and Health Sciences, Aston University, UK.

Final version of published review: Shaw, R.L. On being thrown into phenomenological research: a book review of J.A. Smith, P. Flowers \& M. Larkin (2009) Interpretative phenomenological analysis: theory, method and research. London: Sage. Journal of Health Psychology, 15(2), 310-312. 
Moran, D. (1999). Introduction to Phenomenology. London: Routledge.

Yardley, L. (2000). Dilemmas in qualitative health research. Psychology \& Health, 15, 215-228..

Yin, R. (1989). Case study research: design and methods ( $2^{\text {nd }}$ Ed.). Berveley Hills, CA:

Sage.

Final version of published review: Shaw, R.L. On being thrown into phenomenological research: a book review of J.A. Smith, P. Flowers \& M. Larkin (2009) Interpretative phenomenological analysis: theory, method and research.

London: Sage. Journal of Health Psychology, 15(2), 310-312. 